\title{
APLICAÇÃO DOS PRINCÍPIOS DA FUNÇÃO SOCIAL E DA BOA-FÉ NA JUSTIÇA
} AMBIENTAL

\author{
Humberto Gomes Macedo ${ }^{1}$ \\ Fernanda Araújo Rabelo ${ }^{2}$
}

\section{Resumo:}

Trata o presente artigo da Justiça Ambiental e sua interlocução com a Sustentabilidade e a forma como alguns institutos civis constitucionais devem se conectar com a disciplina. Verificou-se o fundamento para tal conexão, bem como os modelos de aplicabilidade prática, tendo em vista o paradigma do Estado Ambiental. Em relação à metodologia, utilizou-se a pesquisa qualitativa e explicativa, o método dedutivo, análise de referências bibliográficas e documentais, bem como o estudo de caso. Foram identificados e analisados elementos de interdependência entre problemas ambientais e sociais merecedores de dedicação pelos operados do Direito, como incremento da teoria da Justiça Ambiental.

Palavras-chave: Justiça ambiental. Sustentabilidade. Princípios. Função Social. Boa-fé.

\section{APPLICATION OF THE PRINCIPLES OF SOCIAL FUNCTION AND GOOD FAITH IN ENVIRONMENTAL JUSTICE}

\begin{abstract}
:
It deals with the present article of Environmental Justice and its dialogue with Sustainability and how some constitutional civil institutes should connect with the discipline. The foundation for this connection was verified, as well as the models of practical applicability, considering the paradigm of the Environmental State. Regarding the methodology, we used the qualitative and explanatory research, the deductive method, analysis of bibliographic and documentary references, as well as the case study. Elements of interdependence between environmental and social problems worthy of dedication by law operatives were identified and analyzed, as an increment of the Environmental Justice theory.
\end{abstract}

Keywords: Environmental Justice. Sustainability. Principles. Social Function. Good Faith.

\section{INTRODUÇÃO}

Em tempos de quarta revolução industrial, em que os investimentos globais são direcionados especialmente para a tecnologia, não se pode olvidar da preocupação ambiental, uma vez que, apesar dos avanços relacionados à informação, internet das coisas, misto entre o

\footnotetext{
${ }^{1}$ Professor de Direito Civil e Doutorando em Direito Ambiental e Desenvolvimento Sustentável pela Escola Superior Dom Hélder Câmara. Advogado autárquico do Estado de Minas Gerais. Currículo Lattes: http://lattes.cnpq.br/2965597903526871. Email: hgmacedo@ hotmail.com.

2 Advogada e Administradora. Mestranda em Direito Ambiental e Desenvolvimento Sustentável pela Escola Superior Dom Hélder Câmara. Currículo Lattes: http://lattes.cnpq.br/9157068470143085. E-mail: f.araujorabelo@gmail.com
} 
real e o virtual, algoritmos, inteligência artificial, biotecnologia, impressão 3D e manufatura aditiva, ainda existem problemas graves de disposição de rejeitos, manipulação de resíduos, saneamento básico, segurança de barragens, aquecimento global, desmatamento, utilização desenfreada de agrotóxicos, entre outras questões relacionadas ao meio ambiente.

Para tanto, a Justiça Ambiental se concretiza com enfoque no princípio da Sustentabilidade como modelo e norma essencial em todos os ramos do Direito, servindo de medida de equilíbrio entre o econômico e o social.

Dessa feita, questiona-se: como os preceitos do Estado Ambiental podem induzir a uma releitura de outros ramos do Direito - no caso e como exemplo os princípios da Função Social e Boa-fé -, para sua aplicação aos ditames da Justiça Ambiental?

Em relação à metodologia, utilizou-se a pesquisa qualitativa e explicativa, o método dedutivo e realizou-se a técnica de estudo de referências bibliográficas e documentais, especialmente as normas jurídicas afetas à temática.

Para alcance do objetivo, levantou-se a hipótese de que o Estado Ambiental não seja utilizado apenas como parâmetro teórico/filosófico - ou utópico - para as atividades e normas, mas que seja efetivamente o fim prático de todas as condutas privadas e públicas, principalmente no Direito Civil, em uma releitura de seus princípios até mesmo como atividade hermenêutica em prol de adequada Justiça Ambiental.

Dessa feita, assim desenvolveu-se o presente artigo: primeiramente discorreu-se acerca da relação entre a Justiça Ambiental e a Sustentabilidade e sua aplicabilidade na releitura de institutos civilistas e de outras disciplinas jurídicas; ato seguinte, analisaram-se os princípios da Função Social Ambiental e da Boa-fé e sua importância para o direcionamento ao Estado Ambiental; para finalmente apresentar o estudo do caso do Córrego do Onça, localizado em Belo Horizonte-MG.

Afirma-se, portanto, que há emergência para que o novo Estado Ambiental seja constituído no conjunto de regras que não mais evidencie o ser humano como escopo uno, mas com esforços para a proteção da natureza, sob pena de, inclusive, se dizimar a própria humanidade.

\section{JUSTIÇA AMBIENTAL E A SUSTENTABILIDADE}


O mundo já iniciou a quarta revolução industrial, marcada, desta feita, pela fase digital, numa fusão entre a tecnologia e a bioética. É o mundo da robótica, da conexão entre o virtual e o real, da realidade aumentada, dos drones e da ditadura algorítmica.

As três revoluções anteriores foram marcadas pela industrialização (vapor), pela energia elétrica e pela revolução tecnológica, esta simbolizada principalmente pela utilização global da internet. Fato é que essas inovações tecnológicas mudaram a medicina, a escola, o estudo e a pesquisa acadêmica, os processos judiciais e até mesmo os relacionamentos sociais e afetivos. E as tecnologias transformam a nova sociedade formada pelos algoritmos, pela inteligência artificial, internet das coisas, revolução 4.0 (MORAIS, 2018, p. 883), pela biotecnologia, impressão 3D, manufatura aditiva e blocos do minecraft.

Todavia, as disparidades sociais ainda não foram suprimidas. Lixo ainda é produzido em alta escala e jogado nas ruas ao lado, por exemplo, de crianças e cães abandonados. Rios e nascentes ainda são poluídos por esgoto e falta de saneamento básico. Assim, no atual patamar de desenvolvimento, baseado em modelo de crescimento exponencial com uso intensivo dos recursos naturais (água, minério, terras etc.), há impacto de forma desigual aos grupos tradicionalmente social e economicamente vulneráveis. O lixo, a poluição e toda a série de riscos ambientais provocados por mineradoras, agronegócio, indústrias e petrolíferas não atingem a sociedade de forma equilibrada. Fato é que a crise ambiental é genérica e global, estando todos igualmente sujeitos aos seus efeitos nocivos, seus impactos ambientais não são democráticos.

É neste contexto que a Justiça Ambiental se torna cada vez mais importante na tentativa de conectar todas as transformações advindas dessas novidades tecnológicas e as antiguidades sociais que ainda promovem problemas humanos e ecológicos.

Por isso, necessário se faz entender como os preceitos do Estado Ambiental podem induzir a uma releitura dos institutos civilistas, principalmente face aos princípios da Função Social e Boa-fé, para sua aplicação aos ditames da Justiça Ambiental, que assim se conceitua:

Por Justiça Ambiental entenda-se o conjunto de princípios que asseguram que nenhum grupo de pessoas, sejam grupos étnicos, raciais ou de classe, suporte uma parcela desproporcional das consequências ambientais negativas de operações econômicas, de políticas e programas federais, estaduais e locais, bem como resultantes da ausência ou omissão de tais políticas (HERCULANO, 2002, p.2)

Assim, originada nas lutas por questões ambientais, a Justiça Ambiental se concretizou para promover alterações significativas em âmbitos particulares e governamentais com foco na 
proteção do meio ambiente:

Uma noção emergente que integra o processo histórico de construção subjetiva da cultura dos direitos no bojo de um movimento de expansão semântica dos direitos humanos, sociais, econômicos, culturais e ambientais. Na experiência recente, a justiça ambiental surgiu da criatividade estratégica dos movimentos sociais, alterando a configuração de forças sociais envolvidas nas lutas ambientais e, em determinadas circunstâncias, produzindo mudanças no aparelho estatal e regulatório responsável pela proteção ambiental (ACSERALD, 2005, p.223).

E a Justiça Ambiental estuda, justamente, a conexão entre os problemas sociais e ecológicos, detectando a convivência de ambos, pois as evidências e fatores indicam que as áreas mais pobres são também as mais degradadas ambientalmente.

Nesse aspecto, para o autor e poeta espanhol Jorge Riechmann (2003), assim como a economia política se preocupa com os conflitos econômicos, a ecologia política deve se atentar aos conflitos ambientais e as desigualdades sociais.

Existem diversos exemplos que comprovam que a degradação social incrementa problemas ambientais no entorno e vice e versa, o que, denota, inclusive sua denominação como "Justiça Ecológica".

Dessa feita, a Justiça Ambiental, como disciplina que estuda a disparidade ambiental e social, somente pode ser concebida à luz da sustentabilidade como norte das regras e princípios. Daí que se sugere o estudo da Justiça Ambiental sempre com ênfase na sustentabilidade como modelo e norma essencial em todos os ramos do Direito, devendo laborar como balança no equilíbrio econômico e social, e em alcance ao futuro:

Consiste no uso racional e equilibrado dos recursos naturais, de forma a atender as necessidades das gerações presentes, sem prejudicar o seu emprego pelas gerações futuras. Significa, por outra, desenvolvimento econômico com melhoria social das condições de todos os homens e em harmonia com a natureza (SAMPAIO; WOLD; NARDY, 2003, p. 47).

Nesse sentido, como realçado por Freitas (2015, p. 406), “cumpre fazer a sustentabilidade na condição de princípio cogente, não mera faculdade”. Dessa forma, o discurso da sustentabilidade deve ser adotado por todas as áreas jurídicas e sociais, como princípios norteadores das normas e das políticas públicas.

Nesse sentido, Nunes Júnior (2004) acrescenta e reforça a necessidade de uma juridicidade ambiental, por exemplo:

Como se observa, o Estado Ambiental apresenta características que lhe conferem funções (ampliadas) do Estado Liberal e do Estado Social, considerando, sobretudo, a preservação do meio ambiente e a promoção da qualidade de vida, como valores fundantes de uma democracia e de uma nova forma de cidadania (participativa e 
enfim, passa a existir uma juridicidade ambiental) (Nunes Júnior, 2004, p. 300).

Por esse novo paradigma, a economia e desenvolvimento fazem sentido apenas quando ajustados sob as ideias de Sustentabilidade e de Justiça Ambiental, que passam a integrar as esferas social e ambiental de uma forma dialética, concreta e não hierarquizada.

Today, environmental justice and human rights movements are merging together as a global force for social change and democratization. Activists in Europe, the Americas, Africa, and Asia are collaborating to challenge socially and ecologically harmful state and corporate polices concerning hydroelectric power, incineration, and mineral extraction, for example, while offering alternatives for sustainability and social justice (MOHAI; PELLOW; ROBERTS, p . 22) $)^{3}$.

Desse modo, o olhar da Justiça Ambiental é holístico, de forma que as questões ambientais se entrelacem com as sociais e as econômicas, como instrument garantidor do meio ambiente ecologicamente equilibrado:

Os vazamentos e acidentes na indústria petrolífera e química, a morte de rios, lagos e baías, as doenças e mortes causadas pelo uso de agrotóxicos e outros poluentes, a expulsão das comunidades tradicionais pela destruição dos seus locais de vida e trabalho, tudo isso, e muito mais, configura uma situação constante de injustiça sócio- ambiental no Brasil, que vão além da problemática de localização de depósitos de rejeitos químicos e de incineradores da experiência norte- americana, devendo açambarcar também outros aspectos, tais como as carências de saneamento ambiental no meio urbano e a degradação das terras usadas para acolher os assentamentos de reforma agrária, no meio rural. Pois não são apenas os trabalhadores industriais e os moradores no entorno das fábricas aqueles que pagam, com sua saúde e suas vidas, os custos das externalidades da produção das riquezas brasileiras, mas também os moradores dos subúrbios e periferias urbanas, onde fica espalhado o lixo químico, os moradores das favelas desprovidas de esgotamento sanitário, os lavradores no campo, levados a consumir agrotóxicos que os envenenam, as populações tradicionais extrativistas, progressivamente expulsas de suas terras de uso comunal (HERCULANO, 2002, p.6-7).

Outrossim, da mesma maneira que a Boa-fé e a Função Social caminham de mãos dadas na exigência de transparência, confiança, intervenção externa e prevalência da coletividade, fatalmente o contrato, a propriedade, a família, os direitos reais e demais institutos, também terão que se adequar no que tange à sustentabilidade e busca de Justiça Ambiental adequada. Assim, os ramos e princípios do direito privado devem se adequar para, teórica e concretamente, minimizar os impactos provocados pelos resíduos de todo o procedimento econômico e produtivo da atual sociedade contemporânea.

\footnotetext{
${ }^{3}$ Hoje, a justiça ambiental e humana movimentos de direitos estão se fundindo como um força global para a mudança social e democratização. Ativistas na Europa, nas Américas, África e Ásia estão colaborando para desafiar estado social e ecologicamente prejudicial e Políticas corporativas de hidrelétricas energia, incineração e extração mineral,por exemplo, oferecendo alternativas para sustentabilidade e justiça social (Tradução livre)
} 
Os princípios, legislação e enfoque ambiental passam a ser os modelos máximos de condutas e políticas públicas, além das atividades dos particulares, numa tentativa de mais uma arma em prol da Justiça Ambiental.

Nesse ínterim, eis exemplo da conexão entre a Boa-fé (civil-constitucional) com a Prevenção (Ambiental):

O aumento do número de acidentes industriais com repercussões ambientais, a possibilidade cada vez maior de ocorrência de danos ambientais transfronteiriços e o alto potencial destrutivo desses acidentes constituíram o contexto fático suficiente para que a prevenção fosse alçada a princípio jurídico ambiental. (Ribeiro; Thomé; Toledo, 2016, p.70).

Importante ainda indicar que a Justiça Ambiental não deve ser apenas a justa distribuição entre a população humana, mas também entre esta e o restante dos seres vivos que compartilham a Biosfera. Nesse sentido, esclarece Riechmann (2003):

Todos los animales somos hermanos...Baste decir aqui que esa argumentación se basa em enfatizar que, para precisar como há de ser tratado determinado ser vivo, los critérios han de basarse em las capacidades moralmente relevantes que de hecho posee esse ser vivo, y no em su pertenceria a uma espécie determinada; y em la necesidad de evitar la discriminación arbitraria (RIECHMANN, 2003 p.108).

É a mudança de primazia do homem para o próprio globo. O “cidadão" agora é o rio, o passarinho, a muda, a cachoeira.

\section{FUNÇÃO SOCIAL (AMBIENTAL) E BOA-FÉ}

Para fins de introdução a este tópico, insta esclarecer que a utilização da expressão “função socioambiental da propriedade" não é a mais adequada, podendo ser aplicada apenas nas hipóteses em que os interesses social e ambiental coincidam.

Há situações em que tais interesses estarão em confronto; daí porque, sob o aspecto conceitual, melhor será compreender a "função ambiental da propriedade" como desempenho ou cumprimento da finalidade de conservação do meio ambiente como categoria que carrega valor em si próprio, independentemente de deveres outros ligados aos interesses humanos (ARAÚJO, 2017, p.271).

Repete-se o introito sobre o exemplo ocorrido com a Teoria dos contratos que, de exclusivamente privada, passou a ter missão em prol da Dignidade Humana e, hodiernamente,

\footnotetext{
${ }^{4}$ Todos os animais são irmãos ... Basta dizer aqui que este argumento é baseado em enfatizar que, para especificar como um ser vivo deve ser tratado, o critério deve ser baseado nas habilidades moralmente relevantes que o ser vivo realmente possui, e não em sua relevância para uma espécie particular; e na necessidade de evitar a discriminação arbitrária. (Tradução livre).
} 
com a Sustentabilidade, pois o "meio ambiente também deve ser protegido como o direito de defesa da vida, ou melhor, como o local fundamental do desenvolvimento da personalidade humana" (COSTA, 2010, p.116).

Desta feita, a responsabilidade que demanda este agir ético de boa-fé e função social se direciona já agora ao presente e às futuras gerações que viverão essa realidade, numa zelosa "missão confiada [...] a geração presente torna-se guardiã da natureza e das gerações futuras, cujos interesses estão indissociavelmente confundidos"(STEIGLEDER, 2011, p. 160).

Nada mais evidente, assim, do que se integrar a Eticidade, Operabilidade e Concretude - pilares do Código Civil - aos ditames da Justiça Ambiental, com todos as consequências de prevenção, dirigismo, intervenção, obediência, função de controle, interpretação, integração e demais aspectos protetivos dos já tradicionais boa-fé e função social.

Sobre esse liame, Ribeiro, Thomé e Toledo recordam (2016):

Com efeito, pode-se afirmar que realmente foi o Direito civil o marco da ciência jurídica que primeiramente se preocupou com o ambientalismo. Muito antes de surgir o Direito ambiental como espécie autônoma dentro da multiplicidade de disciplinas jurídicas, os civilistas já tratavam de questões da relação do homem com o espaço em que vive (RIBEIRO;THOMÉ; TOLEDO, 2016, p. 12).

Ou seja, o arsenal teórico desta pesquisa se apresenta da mesma forma como ocorrido na Constitucionalização, propondo o estudo que os institutos do Direito Civil não mais interessem apenas aos particulares. Sua modelagem agora é outra. Faz parte de todo organograma social e ambiental.

Eis o princípio da função social que busca-se repaginar como "Função Ambiental", que numa faceta externa permite a intervenção do estado e o dirigismo contratual para que o mesmo cumpra missão coletiva em prol da dignidade humana e da Justiça Ambiental; e na face interna entre os contratantes, em que age no auxílio do princípio da boa-fé antes, durante e depois dos contratos, conforme preceitos dos artigos 421 e 422 do Código Civil:

Art. 421. A liberdade de contratar será exercida em razão e nos limites da função social do contrato, observado o disposto na Declaração de Direitos de Liberdade Econômica.

Art. 422. Os contratantes são obrigados a guardar, assim na conclusão do contrato, como em sua execução, os princípios de probidade e boa-fé.

Neste contexto, deve o direito contratual conciliar a liberdade individual dos contratantes com os propósitos constitucionais de construção de uma sociedade 
ambientalmente segura.

Nesse sentido, a doutrina dá guarida, conforme esforço de Bizawu e Carneiro (2010):

Deve-se ressaltar que as empresas disponibilizam seus produtos e serviços visando o destinatário final delas, ou seja, o povo, que se tratando de pessoas conscientes, elas poderão optar por produtos sustentáveis no mercado tendo como critério de escolha a conduta social das empresas. Esse tipo de conduta é também meio de se garantir a proteção ambiental, porém até para que o consumidor tenha consciência faz-se necessária a educação. Esta é a única ferramenta capaz de garantir que os indivíduos tenham conhecimento de seus direitos e de como exigi-los, único meio capaz de favorecer o exercício pleno da cidadania (BIZAWU; CARNEIRO, 2010,p.122).

Já sobre a Eticidade, traduzida, no artigo 422 do Código Civil (CC) e no Código de Defesa do Consumidor (CDC), se apresenta, principalmente, como Princípio da Boa-fé, exigindo justiça, informação, transparência, equilíbrio e honestidade antes, durante e depois das contratações.

Este princípio exige dos contratantes idoneidade, honradez e lealdade, e exerce três funções no atual ordenamento: (i) Função interpretativa (Art. 113, CC), (ii) Função de integração do negócio jurídico (Art. 421, CC) e (iii) Função de controle dos limites do exercício de um direito (Art. 187, CC).

Para que a boa-fé seja aplicável, seu suporte fático e suas consequências jurídicas precisam ser concretizados. Como concretização da boa-fé, são reconhecidos três círculos de funções da boa-fé (em alemão Funktionskreise): a) completar uma obrigação; b) controlar ou limitar direitos subjetivos; c) corrigir uma obrigação insuportável (FABIAN, 2002, p.61).

A função de Controle, por exemplo, se aplica perfeitamente à Educação ambiental, exigindo condutas e prevenindo (e reparando) danos, "podendo ser considerada como parte de um processo permanente, no qual os indivíduos e a comunidade tomam consciência do seu ambiente e adquirem conhecimentos, valores, habilidades e experiências que os tornem aptos a agir e resolver problemas ambientais presentes e futuros" (MERLONE, 2012).

Essas funções remetem ao estudo da boa-fé objetiva e deveres anexos, visto que decorrentes das funções de interpretação e integração, assim como a função de controle ratifica que o descumprimento ao princípio da boa-fé é ato ilícito gerador de responsabilidade civil:

Art. 113 Os negócios jurídicos devem ser interpretados conforme a boa-fé e os usos do lugar de sua celebração.

Art. 187. Comete ato ilícito o titular de um direito que, ao exercê-lo, excede anifestamente os limites impostos pelo seu fim econômico ou social, pela boa-fé ou pelos bons costumes. Art. 927. Aquele que, por ato ilícito (arts. 186 e 187), causar dano a outrem, fica obrigado a repará-lo.

Sabe-se que as expressões constantes no Código Civil e no Código de Defesa do 
Consumidor tais como: educação e divulgação; informação adequada e clara; a facilitação da defesa; e assegurar informações corretas, claras, precisas e ostensivas são deveres oriundos da boa-fé:

O dever de informar assume papel extremamente relevante na fase das tratativas contratuais, porquanto é neste momento que o consumidor fará sua escolha, cuja liberdade vem expressamente garantida no inciso II do art. $6^{\circ}$. do CDC, seja quanto ao fornecedor com quem irá desenvolver a relação, seja quanto ao bem ou serviço, seja ainda quanto às características de negócio (BARBOSA, 2008, p. 98).

Layrargues (2011) retoma a questão da Eticidade como Função de Controle e Educação:

[...] o verdadeiro consumidor verde, ou melhor, o verdadeiro cidadão consciente e responsável não é aquele que escolhe consumir preferencialmente produtos recicláveis, ou que se engaja voluntariamente nos programas de reciclagem, mas aquele que cobra do Poder Público, por meio de processos coletivos de pressão, que o mercado ponha um fim na obsolescência planejada e na descartabilidade, e, sobretudo, que exige do Estado a implementação de políticas públicas que destruam os mecanismos perversos de concentração de renda[...] (LAYRARGUES, 2011, p.211).

Verifica-se que 'É, portanto, a Boa-fé Objetiva um parâmetro objetivo, genérico, que não está a depender da má-fé subjetiva de alguém, mas de um patamar geral de atuação - de um segurado, locatário, idoso, torcedor, consumidor - que agiria de maneira padrão naquela situação analisada" (MACEDO, 2015, p. 52) e que que pretende, por óbvio, também conceituar e vincular aos ditames do Estado Ambiental, principalmente na atividade hermenêutica dos casos concretos.

A doutrina estrangeira incrementa tal aplicação de princípios, trazendo importante ideia como a da in dubio pro natura que se enquadra integralmente à interpretação aplicada à Boa-fé ambiental sugerida:

Las normas citadasse complementan com el principio in dubio pro natura, para la aplicación e disposiciones legales em matéria ambiental que, em caso de duda, se hará siempre em el sentido más favorable a la protección de la naturaleza. Este principio hermenêutico está contenido em el articulo 395.4, norma que contiene los principios constitucionales en materia ambiental (CAMPANA, 2013, p.13) ${ }^{5}$.

Também, para Cólen e Gomes:

\footnotetext{
${ }^{5}$ As mencionadas normas complementam o princípio in dubio pro natura, para a aplicação e disposições legais em questões ambientais que, em caso de dúvida, sempre serão feitas no sentido mais favorável à proteção da natureza. Este princípio hermenêutico está contido no artigo 395.4, uma regra que contém os princípios constitucionais em questões ambientais" (Tradução livre)
} 
Diante dessa realidade, a sociedade de consumo traz, dentre repercussões outras, igualmente dramáticas como a escassez de água, o extermínio de espécies animais e vegetais, a ocupação populacional irrefreável de áreas outrora ocupadas por florestas e ecossistemas equilibrados, a produção de resíduos que, a seu turno, gera efeitos nefastos outros, como a contaminação do solo, da água e do ar.

[...]

Assim, além de tudo aquilo que é consumido em prol da subsistência, existe uma imensa gama de produtos que foram criados para satisfazer não a necessidade humana, mas aos inesgotáveis desejos humanos e todos eles, independente do fim a que se destinam, estão fadados a, em algum momento de seu ciclo de vida, se transformarem em resíduos. (CÓLEN; GOMES, 2017, p. 267 e 272)

Indaga-se novamente: Quais os impactos dessa compulsão ao consumo face a necessidade de diminuir as diferenças de Injustiça Social e Ambiental?

E mais, a doutrina já começa a se atentar para as mudanças proporcionadas pela "revolução da internet", mudanças de comportamento na vontade, no consumo e na globalização sem fronteiras, além de tantas outras, que, seguramente vão necessitar de cuidado no Estado Ambiental. E "pelo menos teoricamente, é possível que, pela renúncia a algumas de suas liberdades fundamentais os homens sejam suficientemente compensados através dos ganhos econômicos e sociais resultantes" (RAWLS, 2002.p.67).

Morais (2018) "confronta":

Mais do que isso, com a "revolução da internet" ignoram-se as tradicionais fronteiras do Estado Nacional - geográficas (território) e institucionais (direitos e garantias) -, uma vez que a localização das informações armazenadas não necessariamente corresponde ao local de violação de um direito fundamental ou ao lugar de sede da empresa que guarda esses dados. Na realidade, na maioria das vezes os dados são armazenados simultaneamente em diversos pontos do globo com intuito de fornecer redundância e acesso mais rápido aos usuários, independentemente de onde eles estejam localizados geograficamente. Não há mais coincidência entre o lugar da decisão política - Estado Nacional - e instância decisória - poder - e, com isso compromisso com os limites institucionais peculiares à fórmula Estado (Liberal) de Direito no que diz respeito a direitos e garantias clássicas - liberdade, privacidade, igualdade formal, contraditório, ampla defesa etc (MORAIS, 2018, p.886).

Assim, que os princípios civis-constitucionais da Boa-fé e Função Social devem ter função otimizadora, interpretativa e normativa ambiental, devendo exigir para perfeito cumprimento das obrigações não só o estipulado no conteúdo do contrato, na propriedade ou na empresa, mas cobrar os deveres anexos em defesa da Sustentabilidade em mais um esforço na redução das desigualdades verificadas pela (In)justiça Ambiental.

\section{O CÓRREGO DO ONÇA}


No dia 08 de junho de 2019, ocorreu o evento “ $11^{\circ}$. Deixem o Onça beber água limpa" nas margens do Córrego do Onça, bairro Novo Aarão Reis, em Belo Horizonte/MG.

O COMUPRA (Conselho Comunitário Unidos pelo Ribeiro de Abreu) realizará no próximo sábado (08), a partir das $8 \mathrm{~h}, \mathrm{o} 11^{\circ}$ Deixem o Onça Beber Água Limpa - Viver com o Rio Vivendo! Na ocasião será celebrado também os 30 anos do bairro Novo Aarão Reis. O evento tem o objetivo de anunciar à comunidade as intervenções e investimentos realizados na região, além de despertar a atenção de todos para seu enorme potencial - com suas cachoeiras, praias e ilhas -, promovendo e incentivando ações que levem à sua requalificação socioeconômica, ambiental e participativa do baixo Onça. (CBH RIO DAS VELHAS, 2019)

No local, foi possível verificar a ocorrência de evidente problema ambiental - rio poluído - com também flagrante degradação social - casas pré-construídas, lixo, esgoto a céu aberto, campo de futebol "de várzea” abandonado, cheiro ruim, entre outros.

O ribeirão Onça se forma a partir da confluência do ribeirão Pampulha com o córrego Cachoeirinha. Deste ponto até a sua foz, no Rio das Velhas, o ribeirão tem 8,3 Km de extensão e marca a divisa das regiões Norte e Nordeste da capital. Considerado o maior poluidor do Rio das Velhas, o ribeirão Onça expõe, de forma incontestável, a degradação de toda a bacia. Infelizmente, sua beleza natural é escondida debaixo do entulho, lixo e esgoto. (CBH RIO DAS VELHAS, 2019)

E são imagens que impressionam a sociedade e os estudiosos ambientais, pois apesar de haver uma cachoeira de grandes proporções de tamanho e volume que deságua no córrego, no entorno, há uma comunidade paupérrima, sem estrutura sanitária, com crianças e animais sujeitos a doenças e todos os malefícios advindos de poluição ambiental.

Reflete-se acerca do potencial turístico desse ambiente se bem conservado e protegido, principal intuito do movimento " $11^{\circ}$. Deixem o Onça beber água limpa":

Com enorme potencial para lazer e turismo, o Onça tem cachoeiras, praias e ilhas. Porém, várias famílias que residem às suas margens estão permanentemente expostas a diversos riscos, causados pelas enchentes, pelo fluxo de esgoto e o acúmulo de lixo. Nesse contexto, as atividades realizadas no $11^{\circ}$ Deixem o Onça Beber Água Limpa buscam soluções para tais situações. (CBH RIO DAS VELHAS, 2019)

Assim, o movimento pode vir a demonstrar exemplo de aplicação de Justiça Ambiental, entrelaçando as questões social, econômica e ambiental, promovendo, se bemsucedido, a garantia do alcance do desenvolvimento sustentável daquela região para as presentes e futuras gerações, conforme ditames da Constituição Federal.

\section{CONCLUSÃO}

Em decorrência das alterações tecnológicas vivenciadas pelo mundo contemporâneo, 
fez-se necessária a análise da aplicação da Justiça Ambiental como princípio norteador do Estado Ambiental de Direito e sua relação com as recentes modificações tecnológicas, econômicas e sociais, mormente por se tratar de um período cujo contexto se encontra marcado por desastres ambientais e desigualdades humanas significativas.

Dessa feita, analisou-se a forma como os preceitos do Estado Ambiental podem induzir a uma releitura dos institutos civilistas, especialmente os princípios da Função Social e Boa-fé, para sua aplicação aos ditames da Justiça Ambiental como meio de redução de desigualdades sociais, econômicas e ambientais.

Por isso, inicialmente, discorreu-se acerca de alguns institutos do Direito Civil, como a Função Social e a Boa-Fé, e sua necessária interligação com a matéria ambiental como meio garantidor de uma Justiça Ambiental.

Utilizou-se o exemplo do evento destinado à proteção do Córrego do Onça, localizado em Belo Horizonte, em que restou demonstrados que as pesquisas cada vez mais ratificam que as desigualdades social e ambiental se encontram entrelaçadas e são interdependentes para "o bem ou para o mal, para cima ou para baixo".

Desse modo, torna-se importante que todo o arcabouçou jurídico seja voltado para a Sustentabilidade como norma principal de todo o sistema de Direito e que também a principiologia contratual deve ter agora função hermenêutica com fincas ao estudo da Justiça Ambiental para, inclusive, auxiliar na redução das desigualdades sociais e ecológicas.

Dessarte, sugere-se que todos os efeitos advindos dos princípios da Função Social e da Boa-fé no âmbito privado devem agora estender suas ações ao meio ambiente social e ecológico. E vice e versa. Toda a prevenção, informação, lealdade, transparência, se conectam aos princípios ambientais de prevenção, vedação de retrocesso socioambiental e outros, num giro hermenêutico e de aplicação prática efetiva em busca de Sustentabilidade humana e ecológica.

\section{REFERÊNCIAS}

ACSELRAD, Henri. Justiça Ambiental: Narrativas de Resistência ao Risco Social Adquirido in Encontros e Caminhos: Formação de Educadoras(es) Ambientais e Coletivos Educadores. Brasília: MMA, 2005.

ANTUNES, Paulo de Bessa. A recuperação der danos ecológicos no direito brasileiro. 
Veredas do direito, Belo Horizonte, v.14, n.29, p.293-321, mai/ago.2017. Disponível em: <http://www.domhelder.edu.br/revistas/index.php/veredas/article/view/1056>. Acesso em: 31 jan. 2019.

ARAÚJO, Giselle Marques de. Função ambiental da Propriedade: uma proposta conceitual. Revista Veredas do Direito, Belo Horizonte, v.14, n.28, p. 251.276, jan/abr. 2017.

BARBOSA, Fernanda Nunes. Informação: direito e dever nas relações de consumo. São Paulo: Revista dos Tribunais, 2008.

BIZAWU, Sébastien Kiwoingi; CARNEIRO, Fernanda. Cidadania e educação ambiental: diálogo necessário para a efetivação dos direitos fundamentais do homem. Temas de Direito Ambiental e Desenvolvimento Sustentável. REZENDE, Elcio Nacur; STUMPF, Paulo Umberto (coordenadores).Belo Horizonte: Editora O Lutador, 2010.

BRASIL. Código Civil. Lei n. 3.071, de 1 de janeiro de 1916. Institui o Código Civil. Disponível em: <http://www.planalto.gov.br/ccivil_03/leis/2002/110406.htm>. Acesso em: 26 ago 2019.

BRASIL. Constituição (1988). Constituição da República Federativa do Brasil. Brasília: Senado Federal, Centro Gráfico, 1988.

BRASIL. Código de defesa do consumidor. Lei n. 8.078/90, de 11 de setembro de 1990. Dispõe sobre a proteção ao consumidor e dá outras providências. Disponível em: <http://www.planalto.gov.br/ccivil_03/leis/18078.htm>. Acesso em: 26 ago. 2019

CAMARgo, Pedro Celso Julião de. Comportamento do consumidor: a anatomia e a fisiologia do consumo. Ribeirão Preto: Editora Novo Conceito, 2010.

CAMPANA, Farith Simon. Derechos de la naturaliza: ?innovación trascendetal, retórica jurídica o proyecto político? Iuris Dictio, v.13, n.5, 2013. Disponível em:

$<$ http://www.usfq.edu.ec/publicaciones/iurisDictio/archivo_de_contenidos?Documents?iurisD icto_15/iurisdictio_015_001.pdf>. Acesso em: 01 fev. 2019.

CBH RIO DAS VELHAS. $1^{\circ}$ Deixem o Onça beber água limpa. Disponível em < http://cbhvelhas.org.br/noticias/vem-ai-o-11o-deixem-o-onca-beber-agua-limpa>. Acesso em: 26 ago. 2019.

COLEN, Suzana Beatriz Sena Teixeira; GOMES, Magno Federici. Possibilidades legislativas na condução e minimização dos problemas geras pelos resíduos sólidos no Brasil.

Argumenta Journal Law, Jacarezinho-PR, Brasil, n.26, p.265-286, Jan./Jun.2017.

COSTA, Beatriz Souza. Meio ambiente como direito à vida: Brasil, Portugal e Espanha . Belo Horizonte: Editora o Lutador, 2010.

CUNHA, Clarissa de Oliveira Gomes Marques da; AFONSO, Henrique Weuil. Rumo a futuros distópicos? História do direito, pós-colonidade e crítica no Antropoceno. Veredas do Direito: Direito Ambiental e Desenvolvimento Sustentável, v.14, n.30, p.187-213, 
dez.2017. Disponível em:

<http:domhelder.edu.br/revista/index.php/veredas/article/view/1048/711>. Acesso em: 27 jan. 2019.

FABIAN, Christoph. O dever de informar no direito civil. São Paulo: Editora Revista dos Tribunais, 2002.

FERREIRA, Heline Sivini; KAILI, Ana Paula Maciel Costa. A dimensão socioambiental o estado de direito. Veredas do Direito, Belo Horizonte, v.14 n.28, p.13-32 Janeiro/Abril de 2017

FREITAS, Juarez. Sustentabilidade. In: CASTRO, Carmem Lúcia Freitas de; GONTIJO, Cynthia Rúbia Braga; PINTO, Luciana Moraes Raso Sardinha (organizadoras). Dicionário de políticas públicas. vol. 2. Barbacena: EdUEMG, 2015.

HERCULANO, Selene. Riscos e desigualdade social: a temática da Justiça Ambiental e sua construção no Brasil. Encontro da ANPPAS, v. 1, p. 1-15, 2002.

LAYRARGUES, Philippe Pomier. O cinismo da reciclagem: o significado ideológico da reciclagem da lata de alumínio e suas implicações para a educação ambiental. In: CASTRO, Ronaldo Souza de; LAYRARGUES, Philippe Pomier; LOUREIRO, Carlos Frederico Bernardo (org.). Educação ambiental: repensando o espaço da cidadania. 5.ed. São Paulo: Cortez, 2011.

LIPOVETSKY, Gilles. O crepúsculo do dever: a ética indolor dos novos tempos democráticos. Trad. de Fátima Gaspar e Carlos Gaspar. Lisboa: Publicações Dom Quixote, 1994.

MACEDO, Humberto Gomes. Teoria geral dos contratos. 2.ed. Belo Horizonte: Initia Via, 2015.

MACHADO, Paulo Affonso Leme. Direito ambiental brasileiro. São Paulo: Malheiros, 2001.

MERLONE, Tiago. Educação ambiental Unesco 1987. Portal Educação, Campo Grande, 2012. Disponível em: <https://portaleducacao.com.br/biologia/artigos/educacao-ambietalunesco-1987>. Acesso em 28 jan. 2019.

MILARÉ, Edis. Direito do ambiente: a gestão ambiental em foco, doutrina, jurisprudência, glossário. 7.ed. São Paulo: Revista dos tribunais, 2015.

MOHAI, Paul; PELLOW, David; ROBERTS, J. Timmons. Environmental justice. Annual Review of Environment and Resources, v. 34, p. 405-430, 2009.

MORAIS, José Luis Bolzan de. O estado de direito 'confrontado' pela revolução da internet. Revista Eletrônica do Curso de Direito da UFSM, Santa Maria, v. 13, n 3, p. 876-903, 2018. Disponível em: https://periodicos.ufsm.br/revistadireito/article/view/33021. Acesso em: 02 dez. 2019.

NUNES JUNIOR, Amandino Teixera. O Estado Ambiental de Direito. Revista de Informação Legislativa. Brasília, n. 163, p. 300 jul./set. 2004. 
PERLINGIERI, Pietro. Perfis do direito civil: introdução ao direito civil constitucional. 2.ed. Rio de Janeiro: Renovar, 2002.

RAWLS, John. Uma Teoria da Justiça. São Paulo: Martins Fontes, 2002. REALE, Miguel. Lições preliminares de direito. 27.ed. São Paulo: Saraiva, 2002.

RIBEIRO, José Cláudio Junqueira; THOMÉ, Romeu; TOLEDO, André de Paiva. Acidentes com barragens de rejeitos de mineração e o princípio da prevenção: de Trento (Itália) a Mariana (Brasil). Rio de Janeiro: Lumen Juris, 2016.

RIECHMANN, Jorge. Tres principios básicos de justicia ambiental. In: Congreso de la asociación española de ética y filosofía política, 12., 2003, Castellón. Anais,Castellón, 2003.

ROCHA, Anacélia Santos et al. O dom da produção acadêmica: manual de normalização e metodologia da pesquisa. Belo Horizonte: Escola Superior Dom Helder Câmara, 2016.

Disponível em: <http://domhelder.edu.br/uploads/pesquisa/domdaproducaoacademica.pdf> . Acesso em: 26 ago. 2019.

SAMPAIO, José Adércio Leite; WOLD, Chris; NARDY, Afranio. Princípios do Direito Ambiental: na dimensão internacional e comparada. Belo Horizonte: Del Rey, 2003.

SAMPAIO, José Adércio Leite. Teoria do risco ambiental integral e ideologia. Revista Internacional Consinter de Direito, v.01, p.1,2015. Disponível em

$<$ https://editorajurua.com/revistaconsiter/revistas/ano-i-volume-i/parte-1-direitosdifusos coletivos-e-individuais-homogeneos/teoria-do-risco-ambiental-integral-e-ideologia>. Acesso em: 25 jan. 2019.

STEIGLEDER, Annelise Monteir. Responsabilidade civil ambiental: as dimensões do dano ambiental no direito brasileiro. 2.ed. rev.atual.e ampl. Porto Alegre: Livraria do Advogado Editora, 2011.

STUMPF, Paulo Humberto (coord.). Temas de direito ambiental e desenvolvimento sustentável. Belo Horizonte: Editora O Lutador, 2010.

THOMÉ, Romeu. Manual de direito ambiental. 3.ed. Salvador: Juspodivm, 2013.

THOMÉ, Romeu. O princípio da vedação de retrocesso ambiental no contexto da sociedade de risco. Salvador: Juspodivm, 2013.

VIDIGAL, Leonardo Bruno Marinho. O regime jurídico das condições gerais dos contratos. 99f. Dissertação (Mestrado em Direito Civil) - Faculdade de Direito da Universidade Federal de Minas Gerais, Belo Horizonte, 2003. 